\title{
Práticas transidiomáticas na aula de Língua Espanhola: um relato de atividade multimodal na escola pública
}

\author{
Michelle Soares Pinheiro ${ }^{1}$ \\ Universidade Estadual do Ceará \\ michelle040481@hotmail.com \\ Claudiana Nogueira de Alencar ${ }^{2}$ \\ Universidade Estadual do Ceará \\ claunoce@gmail.com
}

\section{Resumo}

Este artigo é baseado em um relato de experiência docente, em que tivemos a pretensão de estimular a reflexividade linguística dos alunos adolescentes da rede pública de ensino da capital cearense. O referencial teórico é pautado nos eixos conceituais: superdiversidade e transidioma (MOITA LOPES, 2013; BLOMMAERT; RAMPTON, 2011); multimodalidade e multiletramentos (JEWITT, 2010; SOARES, 2002; ROJO, 2012). Dessa forma, almejamos escrever como ocorrem os usos transidiomáticos nas práticas sociais dos alunos do $2^{\underline{0}}$ ano do ensino médio na construção de textos multimodais, a partir da perspectiva da superdiversidade e da multimodalidade. Diante do exposto, acreditamos que os usos transidiomáticos devem estar presentes nas práticas discursivas da escola, principalmente nas aulas de língua estrangeira, a fim de sensibilizar os alunos em prol de uma visão sociolinguística emancipatória.

Palavras-chave: Transidioma. Multimodalidade. Experiência docente.

\footnotetext{
${ }^{1}$ Mestranda em Linguística Aplicada pelo Programa de Pós-Graduação em Linguística Aplicada (PosLA) da Universidade Estadual do Ceará (UECE).

${ }^{2}$ Doutora em Linguística pela Universidade Estadual de Campinas (2005) com pós-doutorado na área de Semântica/Pragmática pela Universidade Estadual de Campinas (2010) e atualmente professora titular da Pós-Graduação em Linguística Aplicada (PosLA) da Universidade Estadual do Ceará (UECE).

Horizontes de Linguística Aplicada, ano 15, n. 2, 2016 


\begin{abstract}
This paper is based on a teaching experience, from a perspective of the linguistic reflexivity for high school students of a public school located in Fortaleza, Ceará, Brazil. The theoretical framework is related to these approaches: superdiversity and transidiomatic uses of language (MOITA LOPES, 2013; BLOMMAERT; RAMPTON, 2011); multimodality and multiliteracies (JEWITT, 2010; SOARES, 2002; ROJO, 2012). Thus we intend to show how transidiomatic linguistic uses occur in the social practices of the students from high school of the second degree in Brazil. We will see, in fact, the construal of multimodal texts, from the perspective of the superdiversity and the multimodality. We consider transidiomatic uses as present in the classes, mainly in second language classes, in order to make the students aware of an emancipatory sociolinguistics view.
\end{abstract}

Keywords: Transidioma. Multimodality. Teaching experience.

\title{
1 Introdução
}

Em um mundo globalizado e desterritorializado (MOITA LOPES, 2013), nossa comunicação se constrói com base nas "mutações comunicativas", em que indivíduos e textos multimodais ${ }^{3}$ são móveis e dinâmicos. Por isso, os usos transidiomáticos surgem como construções flexíveis da língua, tendo em vista que não podemos segregar as línguas e separar suas fronteiras.

Nesse sentido, a multimodalidade, para Jewitt (2010), é concebida como a análise de todos os recursos utilizados pelas pessoas nas interações e na comunicação para representar os significados, principalmente os modos não-verbais. A autora enfatiza que a multimodalidade está relacionada com os discursos sociais vigentes, englobando as normas socioculturais, os interesses e as motivações no momento da construção do signo linguístico por parte dos produtores dos signos num contexto social específico. Assim, esse artigo terá por base uma atividade de produção textual multimodal em sala de aula, na

${ }^{3} \mathrm{O}$ termo "multimodais" foi um acréscimo nosso, tendo em vista que todo texto é considerado multimodal, ainda que usufrua apenas de um modo semiótico, o escrito, visto que o tipo, o tamanho e a fonte da letra já se mostram como aspectos potencializadores de sentidos, conforme Bezemer e Kress (2010).

Horizontes de Linguística Aplicada, ano 15, n. 2, 2016 
disciplina de Língua Espanhola na Escola Estadual Mariano Martins ${ }^{4}$, localizada no bairro Henrique Jorge, periferia da cidade de Fortaleza$\mathrm{CE}$, com altos índices de violência e de criminalidade. Dessa forma, essa prática discursiva docente tem como objetivo principal: instigar e sensibilizar os alunos da rede pública de ensino para uma reflexividade linguística (MOITA LOPES, 2013) na sala de aula. Os objetivos específicos foram: a) mostrar como ocorrem os usos transidiomáticos dos alunos do $2^{\underline{o}}$ ano do ensino médio na construção de textos multimodais, sob a perspectiva da superdiversidade e da multimodalidade; b) analisar quais recursos semióticos que os alunos utilizam na construção dos textos multimodais acerca do transidioma nas suas práticas sociais locais.

A intervenção docente aconteceu por meio da aplicação de uma atividade de construção de texto multimodal e da posterior análise das produções multimodais dos alunos, que representaram os usos transidiomáticos nas práticas sociais deles. As produções escritas foram feitas durante a aula de espanhol na escola. Estavam presentes, neste dia, vinte e cinco estudantes, no entanto, atendendo ao pedido deles, permitimos que realizassem a atividade em dupla, o que possibilitou a construção de 15 textos multimodais, já que cinco alunos preferiram fazer o texto individualmente. Para preservar a identidade dos jovens, colocamos apenas as iniciais dos seus nomes, nas transcrições expostas.

\section{Reflexões teóricas sobre transidioma, multimodalidade e multiletramentos}

O conceito de superdiversidade nasceu nas teorias da Sociolinguística da complexidade e da antropologia linguística, com a perspectiva da Semiótica, transcendendo os contextos interacionais. Assim, em meio à globalização e ao multiculturalismo, temos que:

\footnotetext{
${ }^{4}$ Nessa escola, também desempenho a função de professor de diretor de turma, o que me faz ter grande proximidade com os alunos e suas respectivas famílias. Acredito que isso tem favorecido todas as intervenções docentes tanto para a construção de artigos como para a minha pesquisa da dissertação de mestrado.
}

Horizontes de Linguística Aplicada, ano 15, n. 2, 2016 
A superdiversidade é caracterizada por um considerável aumento nas categorias de migrantes, não somente em termos de nacionalidade, etnia, língua e religião, mas também em termos de motivos, padrões e itinerários de migração, processos de inserção dentro do trabalho $e$ mercado imobiliário das sociedades que os acolhem (BLOMMAERT; RAMPTON, 2011, p. 01).

Dessa forma, o conceito de superdiversidade abrange a migração mundial e a dinâmica cultural, uma vez que os processos migratórios possibilitam o surgimento de variedades linguísticas, englobando as mídias e a tecnologia atual, em especial do âmbito da Internet. Blommaert e Rampton (2011) ressaltam que as tecnologias criam impactos nas comunidades hospedeiras, pois as pessoas se comunicam, cada vez mais, pelas mídias e redes sociais digitais, que se configuram como transnacionais, numa perspectiva de ir além das fronteiras nacionais. Isso tem reflexos nas relações sociais, na construção de identidades (ou performatividades) e nas variações linguísticas. Nesse sentido, em virtude de a paisagem linguística (linguascape) variar, adaptar-se e se (re)construir diante dos contextos socioculturais, a superdiversidade amplia os paradigmas dos estudos da linguagem, percebendo as relações de poder nos discursos e nas práticas sociocomunicativas e as ideologias inerentes a estes.

Salientamos que, para Blommaert e Rampton (2011), a superdiversidade desmistifica a antiga concepção de que as línguas são puras, autônomas e estáticas, pois reflete a língua(gem) como artefato ideológico. Nesse viés, Moita Lopes (2013) complementa que a ideia de "pureza linguística" serviu para sedimentar desigualdades sociais em relação à classe social, ao gênero, à raça, dentre outros. Assim, Blommaert e Rampton (2011) defendem que não pode haver essa

\footnotetext{
${ }^{5}$ No original, temos: "Super-diversity is characterized by a tremendous increase in the categories of migrants, not only in terms of nacionality, ethnicity, language, and religion, but also in terms of motives, patterns and itineraries of migration, processes of insertion into the labour and housing markets of the host societies, and so on" (BLOMMAERT; RAMPTON, 2011, p. 01).
}

Horizontes de Linguística Aplicada, ano 15, n. 2, 2016 
idealização de que as comunidades de fala ${ }^{6}$ são estáveis quanto à competência gramatical e à coerência discursiva. Diante disso, os autores enfatizam a diversidade linguística no que tange à existência de línguas mistas e do multilinguajar, uma vez que os falantes podem escolher se, como e quando participam de grupos sociocomunicativos.

Nesse sentido, Blommaert (2012) ressalta que a superdiversidade abrange três conceitos-chave: mobilidade, complexidade e imprevisibilidade, os quais se vinculam à percepção de que os recursos semióticos são mobilizados pelos falantes para realizar determinadas funções na realidade social. Ressaltamos que os recursos semióticos não carregam significados ou sentidos em si mesmos, pois a construção de sentido se dá nas ordens de indexicalidade (BLOMMAERT, 2010; SILVERSTEIN, 2003) que são socialmente construídas. Partindo dessa premissa, quando um indivíduo usa uma determinada estrutura gramatical, isso pode indexicalizar pertencimento a um grupo social marginalizado ou socialmente prestigiado. Para Blommaert (2012), o impacto paradigmático da superdiversidade se encontra na possibilidade de analisar desde o "menor" nível da comunicação humana face a face até o mais alto patamar do sistema linguístico dentro das relações sociais e das práticas transidiomáticas. Essas práticas são entendidas como práticas sociais em que são usados recursos linguísticos fluidos e dinâmicos em meio a fronteiras físicas e cibernéticas, nas quais línguas, textos multimodais ${ }^{7}$ e pessoas estão em constante movimento.

Quanto à construção de significados, Blommaert e Rampton (2011) discorrem que a linguística deve contemplar a significação atrelada à indexicalidade. Ademais, o significado é considerado multimodal por ser constituído de vários modos e recursos semióticos

${ }^{6}$ O conceito de comunidades de fala, segundo Labov (1972), vem sendo substituído pela terminologia de comunidades de práticas, visto que, pela linguística tradicional, a comunidade de fala está relacionada a participação de um indivíduo em um jogo de normas compartilhadas, de forma consciente e inconsciente, compartilhando valores e atitudes semelhantes em relação à língua.

${ }^{7}$ Esclarecemos que, conforme Araújo (2011), todo texto é multimodal, pois um simples negrito ou itálico já modaliza o texto e causa efeitos diferenciados na construção de significados do texto.

Horizontes de Linguística Aplicada, ano 15, n. 2, 2016 
como a linguagem oral, os elementos verbais, as imagens, os sons, os gestos, os movimentos corporais, as expressões faciais, etc. Dessa forma, a indexicalidade e a multimodalidade juntas abrangem aspectos como sotaque, estilo de fala, postura, forma de se vestir, dentre outros.

Para Moita Lopes (2013), as práticas transidiomáticas no Brasil advêm do crescente aumento de imigrantes, principalmente a partir de 2010. O que permite o desenvolvimento de práticas sociais com o chamado "linguajar", que para o autor significa a mistura de línguas diferentes na fala e na escrita. Além disso, acreditamos que o constante acesso à internet, seja por intermédio de lan houses na periferia de Fortaleza-CE ou pelos aparelhos celulares, faz com que, cada vez mais, os jovens estejam conectados às mídias digitais. Inclusive nas dependências da escola, os adolescentes ficam "chateando" com estrangeiros ou se "divertindo", via whatsapp com amigos, explorando também os conhecimentos adquiridos nas aulas de inglês e de espanhol da escola. Assim, podemos relacionar essa realidade ao letramento digital dos alunos. Na esteira de Soares (2002), o mencionado letramento diz respeito ao estado ou à condição dos que adquirem ou se apropriam da nova tecnologia digital e exercem práticas de leitura e de escrita na tela. A autora salienta que vivemos em uma cibercultura, em que há mutações da relação com o saber.

Para Castells (1999), atualmente, as noções de tempo e espaço são vivenciadas pelas pessoas de maneira muito diferenciada por conta do modo como passamos a usar as redes sociais digitais de comunicação e a própria internet. $\mathrm{E}$ isso vem ampliando consideravelmente a mobilidade das línguas, dos textos, dos falantes e dos escritores e, consequentemente, repercutindo na língua(gem) ou, nos termos do autor, no nosso linguajar. Dessa forma, os discursos e artefatos culturais de outros povos, especialmente das línguas supracitadas, se imbricam nas suas práticas sociais cotidianas. Assim, a língua como rizoma refere-se a uma "trama instável de fluxos que só ganha vida quando as pessoas e suas subjetividades e histórias são consideradas nas práticas sociais múltiplas e situadas de construção de significado em que atuam" (MOITA LOPES, 2013, p. 104). Nessa concepção, as pessoas vivem em zonas de contato ou de fronteira, ou seja, as pessoas cruzam as fronteiras físicas e virtuais e estas as aproximam, a despeito de haver um contato concreto. Acrescentamos 
as fronteiras simbólicas como raça, gênero e sexualidade, esmiuçadas por Silva (2013), as quais fomentam o conditio das pessoas nas práticas sociais. A língua, para Moita Lopes (2013), é usada transidiomaticamente nas práticas linguísticas locais como um recurso comunicativo multissemiótico. Nesse ínterim, Moita Lopes (2013) cita como exemplos de uso transidiomático do português: a comunicação digital, os artefatos culturais do rap e as propagandas da periferia brasileira, que são permeadas por performances ${ }^{8}$ identitárias. Nesse sentido, os usos transidiomáticos são capazes de tornar nossas identidades cada vez mais fluidas e dinâmicas.

Sob essa perspectiva, correlacionamos o conceito de superdiversidade com a teoria dos multiletramentos, que, para Rojo (2012), advêm do caráter multimodal ou multissemiótico (hipermidiático) das comunicações atuais, da multiplicidade de culturas em decorrência da globalização das informações e dos bens, da multimodalidade dos textos e da multiplicidade de imagens por consequência das TCI (Tecnologias de Informação e Comunicação). Royce (2006) acrescenta que os multiletramentos têm sido foco de discussões recentes que os apontam como uma necessidade para o ensino no futuro, em especial para os contextos educacionais de segunda língua, assim como ocorre nas aulas ministradas na rede pública de ensino. Royce (2006) considera que os multiletramentos se relacionam ao multilingualismo pessoal e social e sugere também que os efeitos da globalização de práticas de multiletramento acontecem em contextos multiculturais e criam uma metalinguagem em áreas da comunicação e da representação, dentro de uma nova pedagogia.

Segundo o New London Group (2006 [1996]), o letramento vem sendo ampliado com a concepção de multiplicidade de discursos, o que concerne a dois aspectos: a) a pedagogia em prol do letramento deve abranger os diversos contextos sociolinguísticos, as múltiplas culturas e a pluralidade de textos que circulam nas sociedades globalizadas; b) a pedagogia do letramento deve englobar a variedade de formas de textos associados às tecnologias de informação e à

8“Hoje, as identidades são vistas como performances, atos que linguisticamente instituem sua referência no mundo, em vez de meramente descreverem ou constatarem um estado de coisas anterior e exterior" (SILVA, 2013, p. 150).

Horizontes de Linguística Aplicada, ano 15, n. 2, 2016 
multimídia, bem como à proliferação de canais e de meios de comunicação atrelados aos suportes e à diversidade cultural e subcultural.

Jewitt (2010) complementa que a multimodalidade compreende a comunicação e a representação em toda a amplitude da linguagem, incluindo as formas usadas pelas pessoas como imagens, gestos, olhar, postura e a relação entre eles. Essas formas servem de suporte para o discurso, com o objetivo de modificá-lo ou reforçá-lo. Assim, o conceito de multimodalidade faz inferir que a linguagem é parte de um conjunto multimodal, pois a língua(gem) é tida como um modo significativo de comunicação, em especial no contexto de ensino e de aprendizagem. Desse modo, a multimodalidade abrange uma multiplicidade de modos que possuem potencial igualitário para contribuir com o significado, além desse conceito envolver todas as interações sociais entre os indivíduos. Assim, "os textos multimodais são a combinação estratégica e deliberada de elementos para alcançar uma função comunicativa em um contexto particular e em um momento particular" (BULL; ANSTEY, 2010, p. 29) ${ }^{9}$. Os autores acrescentam, quanto à produção e ao consumo dos textos multimodais, os seguintes aspectos a serem considerados: os propósitos da leitura e da escrita; o que a audiência ou o leitor sabe e traz para o texto; o contexto ou condições em que o texto está; os recursos disponíveis para usar na leitura e na escrita.

Paralelamente aos estudos de multimodalidade, Moita Lopes (2013) enfatiza a necessidade de repensar a língua como sistema de comunicação, que vislumbre as práticas sociais locais, em que as línguas são consideradas produto de atividades sociais e culturais em que as pessoas se engajam. Ao tratar das práticas sociais, podemos relacioná-las ao conceito de letramento, pois este envolve práticas sociais, culturais e discursivas de um determinado grupo social, o qual utiliza a escrita e a leitura como sistema simbólico e, também, na condição de tecnologia em contextos e em situações específicas do cotidiano (KLEIMAN, 2008).

${ }^{9} \mathrm{Na}$ versão original: "Multimodal texts are the deliberate and strategic combination of elements to achieve a particular communicative function in a particular context at a particular time" (BULL; ANSTEY, 2010, p. 29).

Horizontes de Linguística Aplicada, ano 15, n. 2, 2016 
Sob a ótica de Moita Lopes (2013), os letramentos digitais se corporificam como uma (r)evolução das relações, pois possibilitam usar as línguas transcendendo as fronteiras físicas e digitais em práticas discursivas transidiomáticas, sem territórios fixos e estanques, para compartilhar e socializar conhecimentos, discursos e ideologias. Assim, as práticas sociais envolvem identidades em construção (ou performances identitárias), visto que redesenhamos a própria identidade por meio da transidiomaticidade, em consequência das variáveis de tempo e de espaço.

\section{A sala de aula: o relato da experiência docente e a análise dos textos multimodais dos alunos}

Inicialmente, a abordagem docente na sala de aula começou com a explicação sobre as variações linguísticas ${ }^{10}$ da língua espanhola. Foi abordado que antigamente estudávamos o espanhol peninsular ${ }^{11}$, negligenciando as variações do idioma na América Latina e em outras regiões como os Estados Unidos ${ }^{12}$ por meio do Spanglish ou Espanglês (dialeto falado por descendentes ou imigrantes de países latinoamericanos, principalmente nas regiões da Flórida, Geórgia, Texas, Califórnia e Nova York).

A priori, os alunos se mostraram empolgados e comentaram algumas experiências virtuais que eles tiveram e/ou têm ao seguir artistas pelo Facebook. A aluna G.K.P.A., por exemplo, relatou que se

\footnotetext{
${ }^{10}$ As variações linguísticas já haviam sido abordadas em outras aulas, inclusive em virtude de o livro didático Síntesis de Martin (2010) contemplar variantes do espanhol da América Latina, como o "voseo". Dessa forma, os alunos já estavam familiarizados com a temática.

${ }^{11}$ Santos; Meneses (2010) fazem uma abordagem sobre as Epistemologias do Sul, que dizem respeito à reflexão de que, durante séculos, preponderou a soberania epistêmica da ciência moderna, por meio da exclusão e do silenciamento de povos e culturas que foram dominados pelo capitalismo e colonialismo.

${ }^{12}$ Nos Estados Unidos, há um grande o número de imigrantes de origem hispano-americana, tais como mexicanos, cubanos e porto-riquenhos, todos eles são falantes de língua espanhola.
}

Horizontes de Linguística Aplicada, ano 15, n. 2, 2016 
comunica com integrantes do grupo mexicano Rebelde ${ }^{13}$ e que usa "tranquilamente" (sic) o "portunhol" com os artistas, que a compreendem bem. Assim, eles citaram várias situações de transidioma que eles, de forma direta ou indireta, praticam ou têm acesso.

Com base no relato dos alunos, explicamos o que seria o transidioma e mostramos o exemplo de textos multimodais extraídos de Moita Lopes (2013), tais como o fragmento a seguir de uma mensagem eletrônica entre um espanhol e um brasileiro, em que prevalece o uso transidiomático do "esportinglês" (uma mistura pragmática dos idiomas espanhol, português e inglês) com o objetivo de estreitarem os laços de amizade e empregarem frases ou palavras dessas línguas, ludicamente. De acordo com o autor:

\author{
Mi queridinho, \\ That will be wonderfull to meet you at the airport, you \\ bighead, and I'll be delighted to have breakfast with you at \\ the hotel. \\ Besos y hasta mañana (MOITA LOPES, 2013, p. 114).
}

Em seguida, mostramos para os estudantes o cartaz de uma propaganda com o uso transidiomático do "portinglês" (figura 1), em que há uma mistura de elementos lexicais do Português com o Inglês com a finalidade de atrair clientes e valorizar a mercadoria, conforme Moita Lopes (2013):

${ }^{13} \mathrm{RBD}$ ou Rebelde foi um grupo musical mexicano surgido em 2004, na
novela adolescente de mesmo nome, considerado o maior fenômeno do pop
mexicano no mundo e da música latina. Horizontes de Linguística Aplicada, ano 15, n. 2, 2016 
Figura 1: Propaganda na periferia brasileira

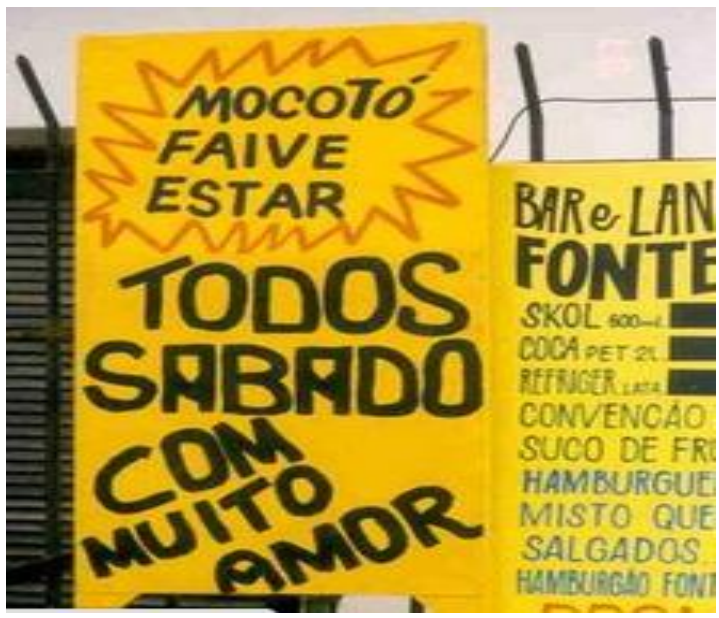

Fonte: MOITA LOPES, 2013, p. 117

Com base nos exemplos acima, pedimos que os alunos construíssem um texto multimodal ${ }^{14}$. Percebemos que a aluna R.M. (figura 2) e a dupla C.F. e K.S. (figura 3) utilizaram o inglês para diferenciar o banheiro feminino (woman) do masculino (man). Em ambos textos, as alunas usaram de elementos semióticos para fazer a distinção de gênero, em um deles havia o desenho do homem e da mulher, já o outro faz uma diferenciação pelas cores rosa e lilás (socialmente construídas como indexicalizadoras do gênero feminino ou da performance identitária do feminino) e o azul com amarelo, representando o banheiro masculino. Percebemos, de acordo com Louro (2014), que a escola ainda fomenta práticas de escolarização dos corpos e das mentes, em que, desde cedo, os alunos aprendem o que se deve ou se pode fazer e usar uma menina e um menino. Assim, os alunos criaram imagens e usaram do recurso semiótico das cores e dos símbolos para transmitir significados. Além disso, observamos que o

${ }^{14}$ Saliento que já desenvolvo minha pesquisa de mestrado com estes alunos desde o início de 2015 sobre multimodalidade e letramento multimodal crítico, por isso tais terminologias já são conhecidas por eles. 
banheiro feminino é um pouco menor que o masculino, possivelmente a autora do texto multimodal tenha feito, ainda que inconscientemente, essa diferenciação para passar a ideia de dominação ainda existente dos homens em relação às mulheres. No texto multimodal de C.F. e K.S. (figura 3), há também mais abaixo um desenho de um restaurante com as palavras "self-service", termo já bastante conhecido pelos brasileiros, e a saudação espanhola "Buenos días", como maneiras de atrair a clientela e divulgar o produto comercializado. Assim, os autores mostram como o transidioma "esportinglês" está presente no cotidiano deles, tanto pelas imagens dos banheiros como pela do restaurante.

Figura 2 - Texto multimodal produzido por R.M.

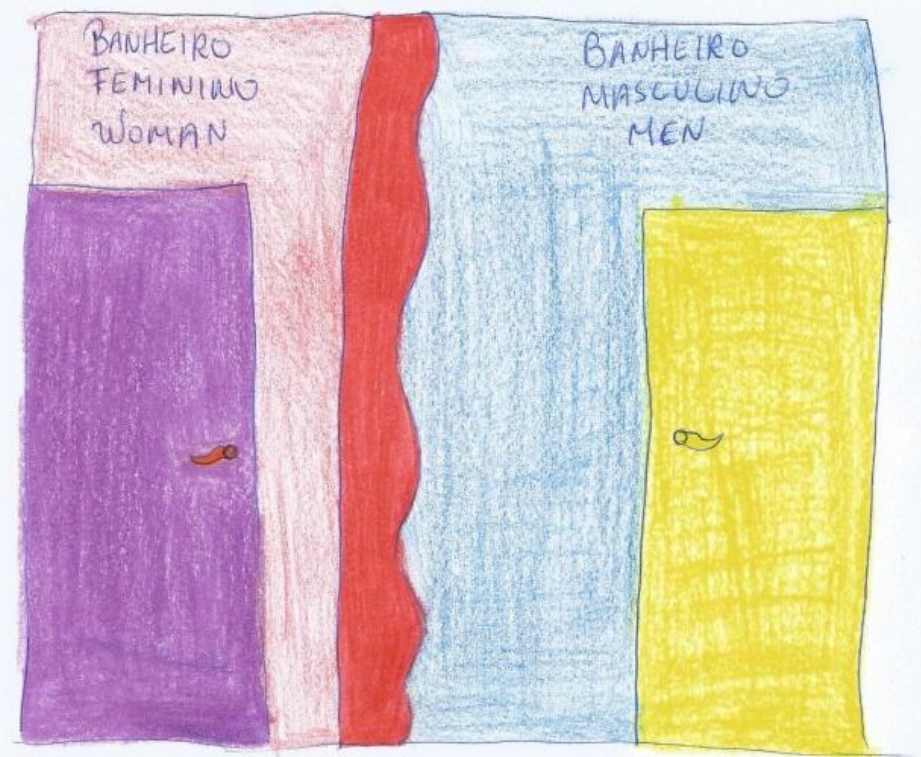

Horizontes de Linguística Aplicada, ano 15, n. 2, 2016 
Michelle Soares Pinheiro; Claudiana Nogueira de Alencar

Figura 3 - Texto multimodal produzido pela dupla C.F. e K.S.
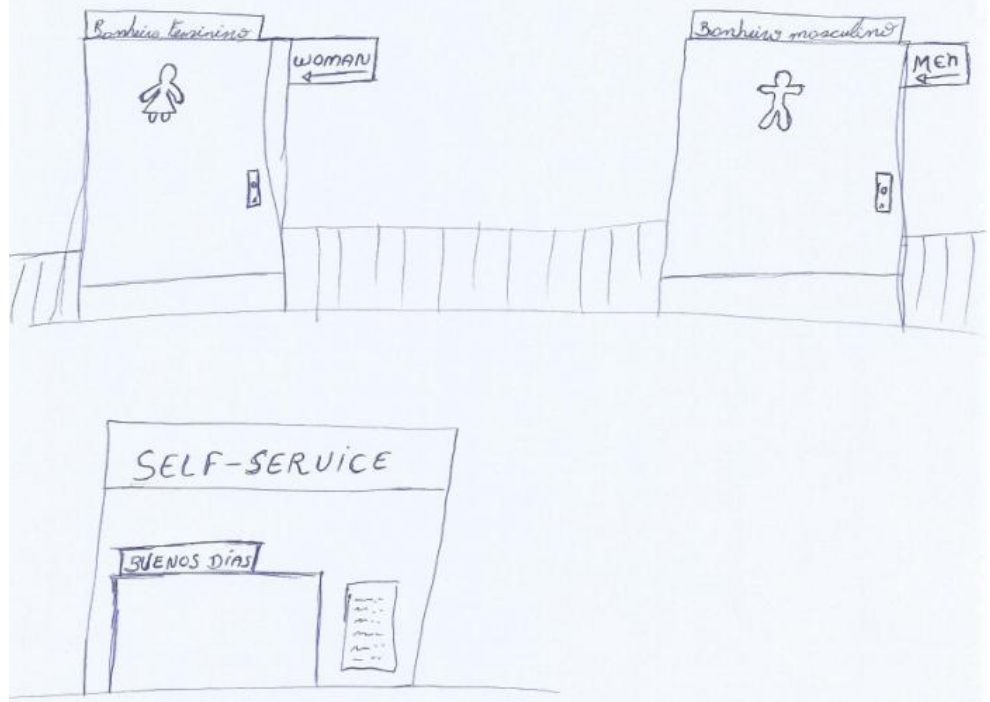

A aluna A.C.F.C.R. constrói um texto multimodal (figura 4) que se assemelha às conversas por meio whatsapp das tecnologias atuais de telefonia móvel, representando as interações virtuais intermediadas pelas mídias digitais. Existem no texto da aluna elementos transidiomáticos do "portinglês" nas palavras brother, beach, amazing e girls, bem como há expressões sociodiscursivamente construídas por pessoas jovens como "E aí brother" e "pegar uma onda". Além disso, a palavra "Partiu" faz referência aos multiletramentos, em especial ao letramento digital, já que este termo é muito empregado nas despedidas nos diálogos das mídias virtuais.

No texto da dupla B.L.Q.B. e I.I.N.P. (figura 5), percebemos o uso transidiomático do "esportinglês", em que o inglês surge com um cunho valorativo e, ao mesmo tempo lúdico e despojado, tornando o diálogo interessante para os interatuantes /interlocutores, havendo a presença de corações e "emotions" (as famosas "carinhas" da Internet), imagens típicas da linguagem midiática, o que possibilita constatarmos 
a proximidade afetiva (nem que seja virtual) dos interlocutores. Na parte inferior do texto, é possível ver uma placa de salão de beleza com a presença do "portinglês", pois usufrui de palavras da língua inglesa como salon, beauty, já o título "Divas d'Gal", segundo os autores, serve para focar nas clientes mulheres heterossexuais, os travestis, os transexuais e os transgêneros, em virtude do termo "divas". Ademais, há marcas de oralidade e reducionismo das palavras nos dois textos multimodais, que se configuram como características da linguagem nas redes sociais virtuais, em virtude da comunicação instantânea, automática, curta e rápida. Além disso, por uma perspectiva multimodal, vimos que o layout e design do texto se assemelham à estrutura de um celular ou smartphone ou ainda à caixa de diálogo do facebook. A dupla B.L.Q.B. e I.I.N.P e a aluna A.C.F.C.R. empregaram elementos verbais, sendo que a última aluna se aproveita um pouco mais dos recursos imagéticos, inclusive a estudante desenha os ícones da caixa de bate papo da internet e, na parte de baixo, há a frase "Digite aqui", a fim de reproduzir um telefone móvel na construção de sentidos do seu texto multimodal. 
Michelle Soares Pinheiro; Claudiana Nogueira de Alencar

Figura 4 - Texto multimodal produzido por A.C.F.C.R.

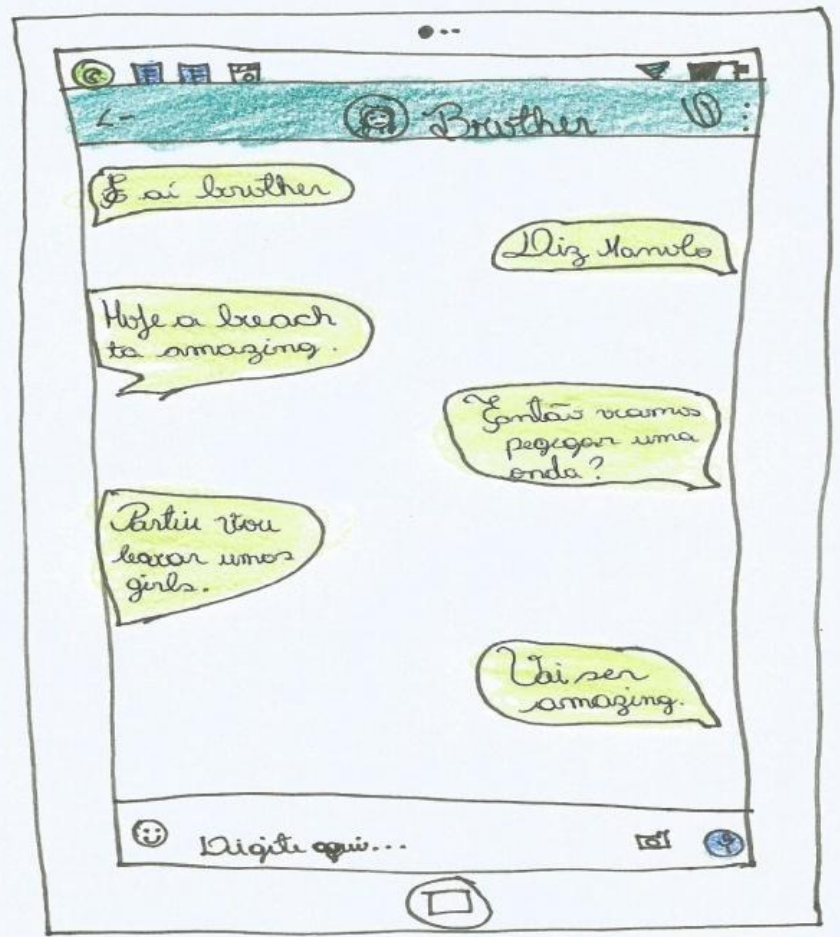


Figura 5 - Texto multimodal produzido por B.L.Q.B. e I.I.N.P.
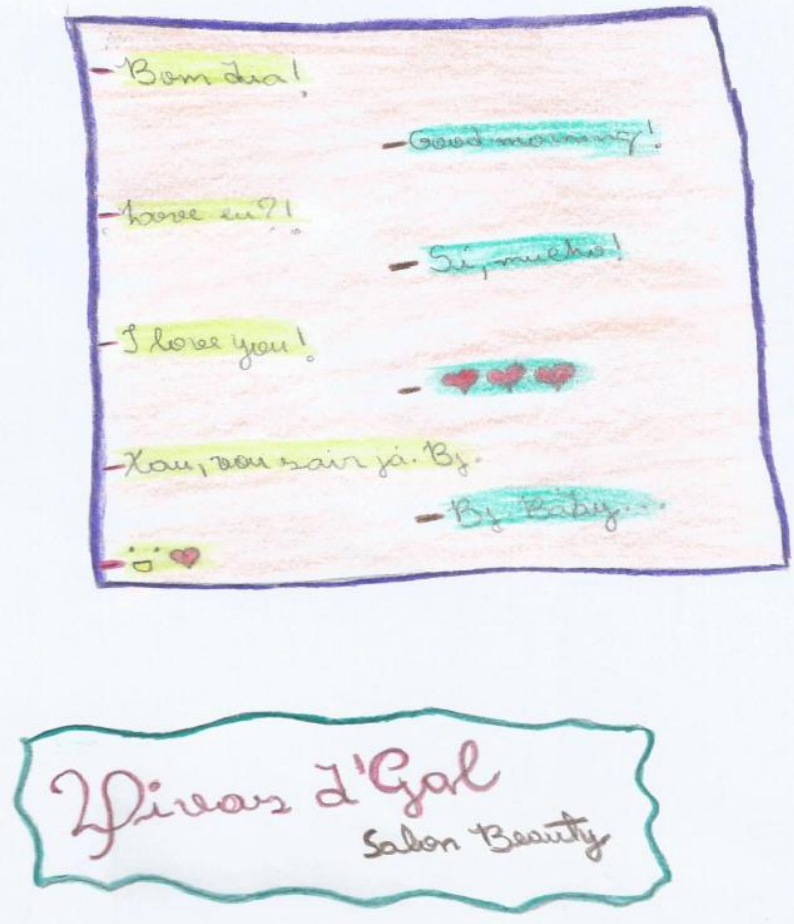

No texto multimodal, representado pela figura 6, a língua inglesa é exposta como uma língua de prestígio, por isso A.M. a escolheu para dar nome ao salão de beleza do seu texto. Essa prática transidiomática do "portinglês" é muito comum nos bairros ${ }^{15}$, onde os

${ }^{15}$ A escola E.E. Mariano Martins fica localizada no bairro Henrique Jorge. Quanto aos alunos, alguns moram no mesmo bairro da instituição de ensino e outros residem nos bairros adjacentes, tais como: Austran Nunes (também conhecido como Alto do Bode), Pici, Dom Lustosa, João XXIII, Jockey Club e Genibaú. As referidas localidades possuem altos índices de violência, em decorrência principalmente do grande número de pessoas que usam drogas Horizontes de Linguística Aplicada, ano 15, n. 2, 2016 
alunos moram e onde fica localizada a escola. O aluno A.M. usou o recurso semiótico da imagem e o nome do estabelecimento comercial com elementos verbais. Já a dupla de alunas G.M. e A.A., no texto da figura 7, escreveu com letras grandes a expressão "swag estilo", na qual o termo em inglês é uma gíria inglesa muito utilizada nas redes sociais, denotando algo interessante ou "legal", o que nos possibilita ver a inserção das alunas nas redes sociais virtuais e como o "portinglês" se coloca presente nas interações sociais deles.

Figura 6 - Texto multimodal produzido por A.M.

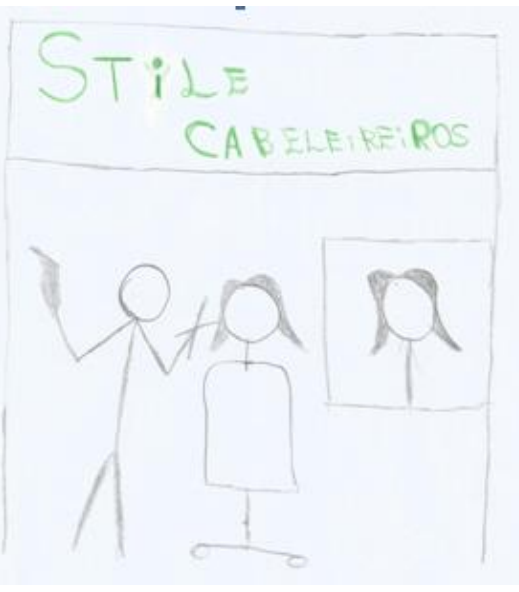

\section{Figura 7 - Texto multimodal} produzido pela dupla G.M. e A.A.

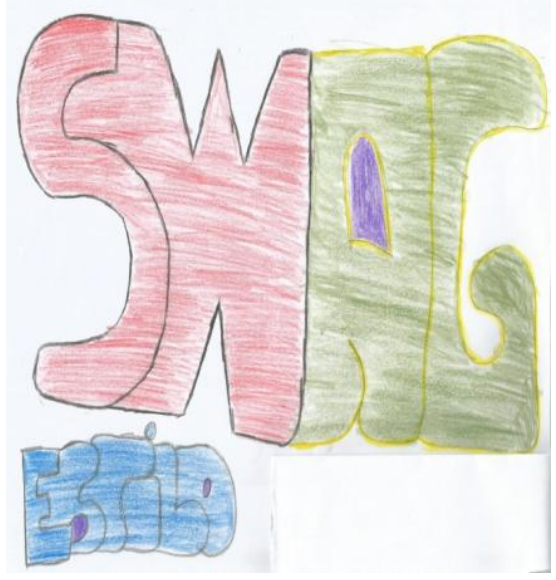

O texto multimodal construído pela dupla M.A.F.R. e G.K.P.A. (Figura 8) apresenta o "esportinglês" por meio de uma espécie de tempestade de ideias, em que as alunas expuseram palavras e expressões dos idiomas: inglês (stop, I, you, black Friday, morning, my princes), e espanhol (besos) e português (verão, ah, e, até, meu). Além disso, há traços de "cearês" (termo dito pelas autoras do texto

ilícitas e estão envolvidas no tráfico de drogas. Por isso, estes bairros são estigmatizados até mesmo pelos próprios estudantes.

Horizontes de Linguística Aplicada, ano 15, n. 2, 2016 
multimodal), que representam as variações linguísticas, dentro da língua portuguesa, construídas, de forma sócio-histórica, pelos cearenses, ao longo dos anos, porém, muitas vezes, estigmatizadas e desprestigiadas em nosso país. O "cearensês" está evidente nas expressões "fi duma égua", "zói" e "marróia", bem como percebemos nitidamente marcas de oralidade, o que nos possibilita inferir que as referidas expressões se mostram presentes nas práticas sociais das estudantes. A dupla ainda coloriu o quadro e inseriu o desenho de um coração na frase "I love you", em substituição ao verbo, o que é muito comum entre os jovens. Também chamamos a atenção para o desenho do sol em torno da palavra verão, pois a aluna usa recursos imagéticos para enfatizar significados, assim como ocorreu na palavra stop, em que há uma espécie de moldura. Além disso, uma das alunas deixou uma marca de batom na folha de papel para representar os besos do texto.

A dupla B.A.C. e M.D.S.B. (figura 9) também usufruiu do "esportinglês" por meio de um quadro com palavras soltas e coloridas com influências do inglês, já que estes termos não obedecem exatamente à "ortografia gramaticalmente correta" do idioma, tais como: "estily" (style), "lovy" (love), , "hamburg" (hamburger), "chocol" (chocolate), "babe" (baby), "ony" (one), "seventi" (seventy). Os alunos também usaram palavras inglesas comuns no cotidiano deles como brother, more, boy e Friday, além de palavras do espanhol como tiempo, bellesa (cuja forma correta seria belleza). Quanto ao português, há palavras como "esfregar", "paixãozão" e "amorzim". As duas últimas palavras representam, respectivamente, o aumentativo irregular e o diminutivo com redução da própria fala. Quanto ao termo "sushy" (sushi) vem do japonês arcaico, mas já se tornou palavra comum no cotidiano de muitos, por ser uma iguaria muito apreciada no Brasil. Por último, esclarecemos que não conseguimos compreender a palavra "enbyhiyy", por isso perguntamos para os autores do texto o que seria essa palavra e estudantes B.A.C. e M.D.S.B. nos responderam que se tratava da palavra English, que eles escreveram errado propositadamente como uma forma de criticar a supremacia da língua inglesa, em detrimento das outras. Dessa forma, percebemos que as grafias "incorretas" foram um instrumento de crítica social para atender aos propósitos dos autores. 
Michelle Soares Pinheiro; Claudiana Nogueira de Alencar

Figura 8 - Texto multimodal produzido pela dupla M.A.F.R. e G.K.P.A.

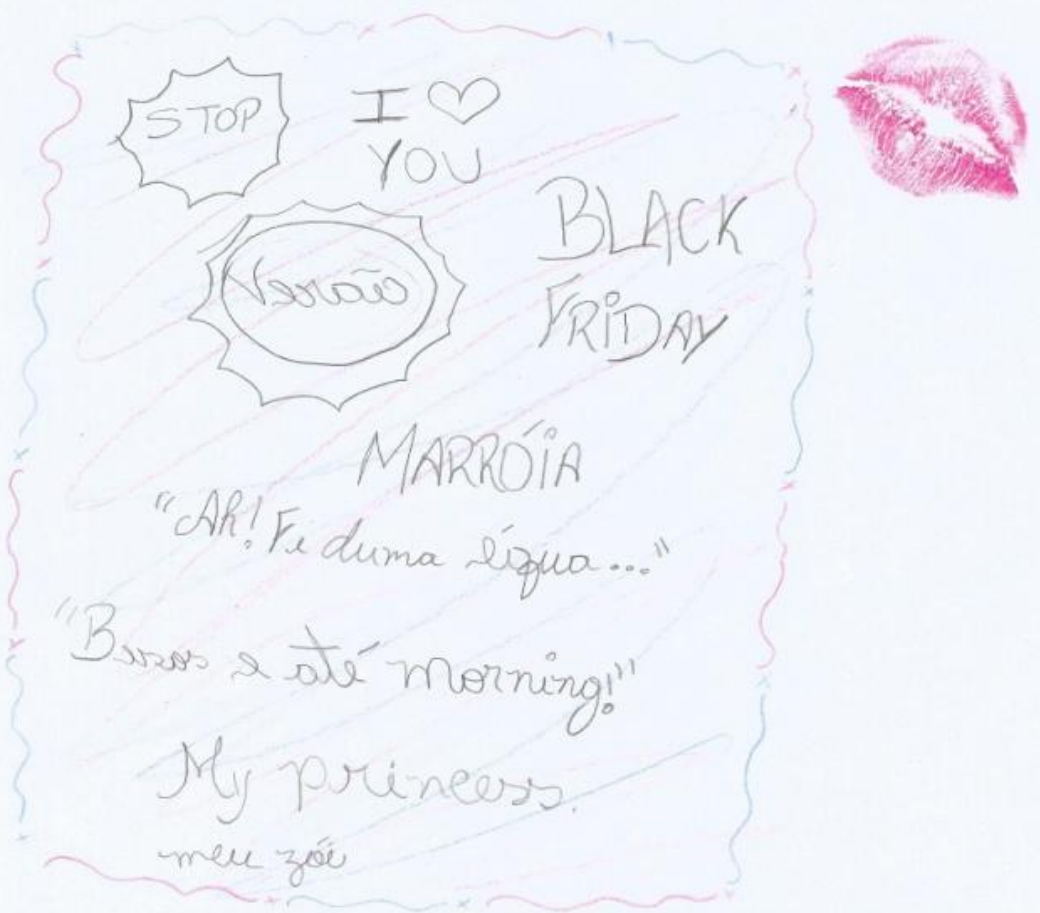


Figura 9 - Texto multimodal produzido pela dupla B.A.C. e M.D.S.B.

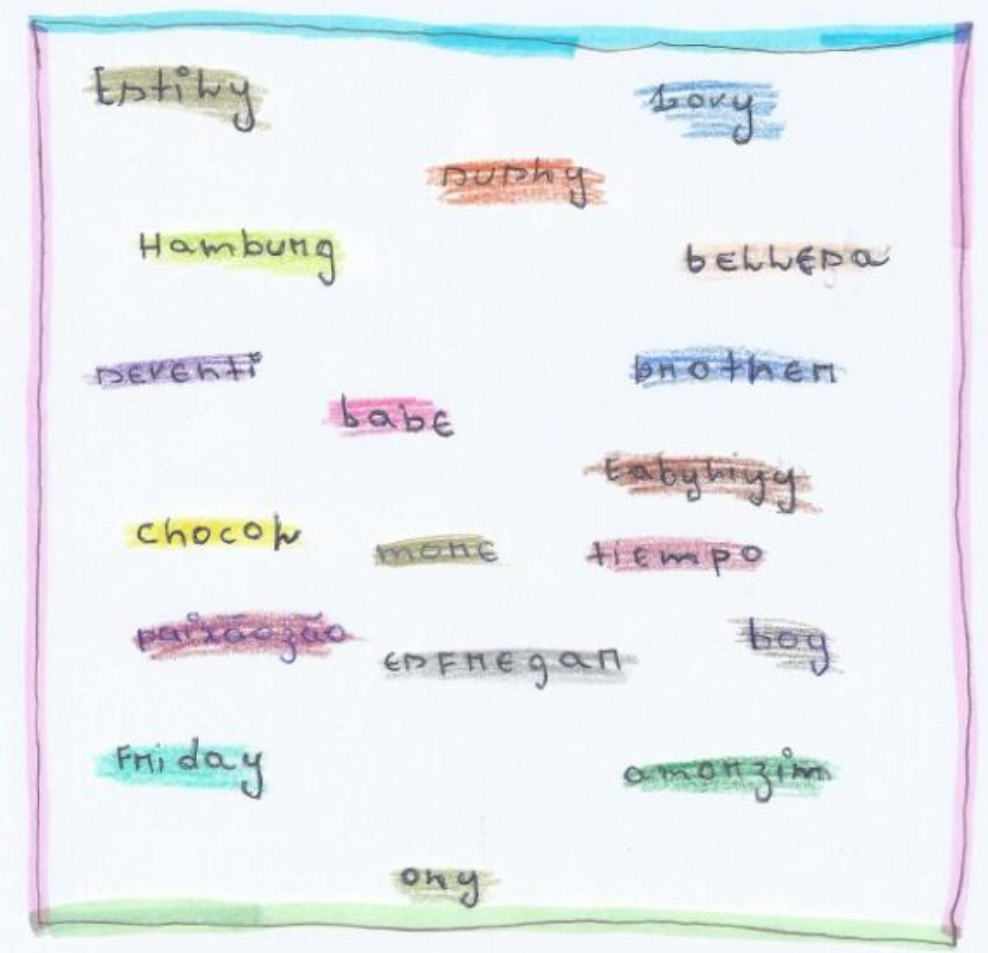

Nos textos multimodais seguintes do aluno M.L e da dupla E.S e P.H, percebemos o uso transidiomático do "portinglês" com a junção de palavras do inglês, como, na figura 10, fast e, na figura 11, love, bem como os termos "fudi", “ai", "iu”, que trazem uma pronúncia aportuguesada e com um tom humorístico, o que nos lembrou um pouco o cearensês do filme "Cine Holliúdi", sucesso em 2013. Em ambos os textos, a multimodalidade é identificada pelos elementos verbais em tamanho maior e coloridos, podendo passar essa ideia de despojamento e graça na mensagem transmitida, bem como realçar e destacar os sentidos. 
Figura 10 - Texto multimodal produzido por M.L.

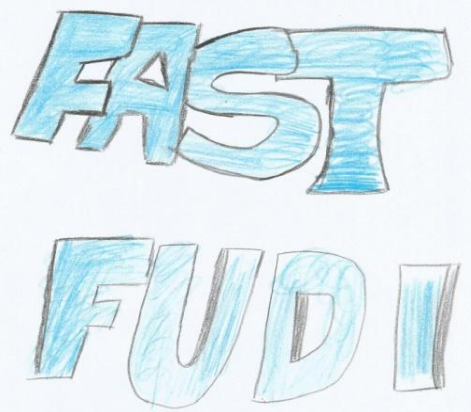

Figura 11 - Texto multimodal produzido pela dupla E.S. e P.H.
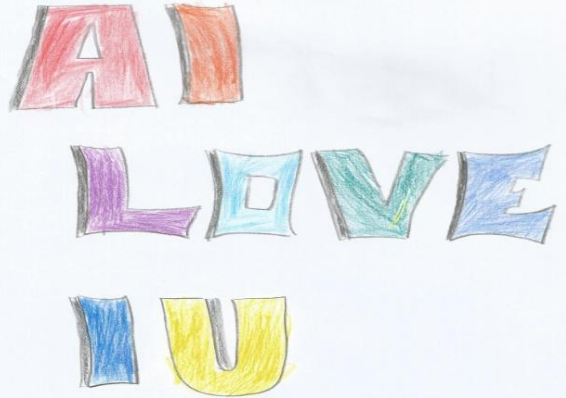

Nos textos multimodais das duplas E.O. e G.D. (figura 12) e M.R. e G.M. (figura 13), percebemos que o uso transidiomático do "esportinglês" tem um objetivo romântico, pois, no primeiro texto, há trechos de músicas espanholas com algumas palavras em português como "tiritas par ti corazón partío", "uma aventura es mais divertido si tem lá peligro" e "eres para mi uma deusa, fruta proihbida, pero deciosa". Há também outros termos do espanhol como eres, hermoso, gracias, niño. Além disso, no texto de E.O. e G.D., há uma simulação de diálogo entre um casal, possivelmente de namorados, com termos extraídos do inglês como you, blackinho, love e boys. A construção "Ai love" refere-se realmente ao sentimento do interlocutor e mostra uma transposição da pronúncia para a escrita, bem como a forma carinhosa "blackinho" para chamar o outro interlocutor de "pretinho". Pela multimodalidade, é possível identificar os elementos imagéticos das flores, o que acentua o caráter romântico do texto, além da diferenciação das cores, dando saliência às falas, em detrimento do fundo amarelo, criando uma configuração estética de cartão romântico. Ademais, identificamos símbolos de músicas, ao lado dos fragmentos das canções, servindo para passar, semioticamente, musicalidade, para os leitores do texto. No texto dos alunos M.R e G.M. (figura 13), é de conhecimento de todos da sala que eles são um casal de namorados, o que pode ser percebido no texto criado pela aluna M.R. para o seu 
namorado G.M. como uma declaração de amor, segundo a própria aluna, que usufruiu do spanglish ou espanglês, terminologia que mostra a mescla de elementos lexicais do espanhol (yo estoy enamorado por) e do inglês (you). A aluna M.R. construiu significados no texto, os quais foram enriquecidos pelos corações em volta da mensagem, emoldurando o texto.

Figura 12 - Texto multimodal produzido pela dupla E.O. e G.D.

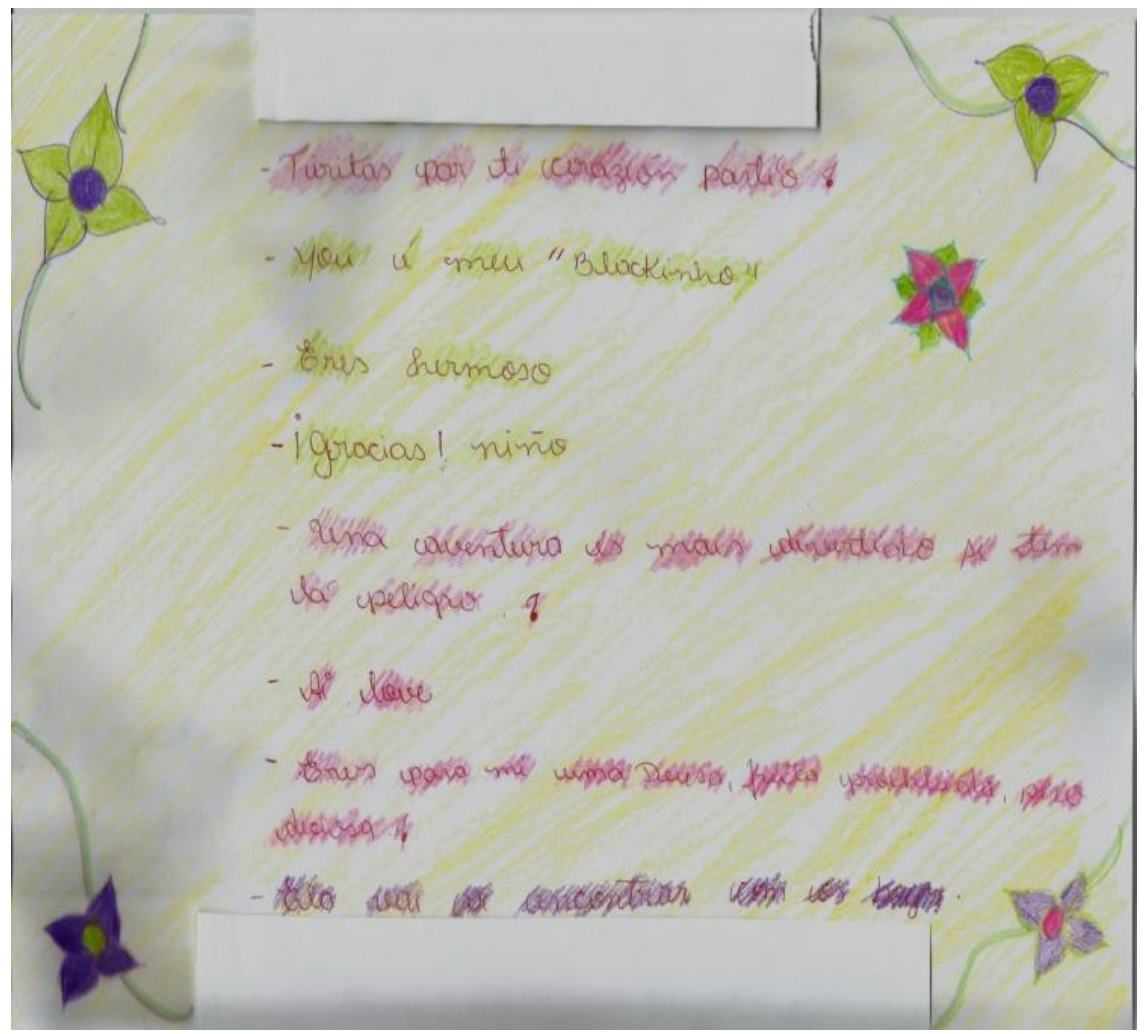

Horizontes de Linguística Aplicada, ano 15, n. 2, 2016 
Figura 13 - Texto multimodal produzido pela dupla M.R. e G.M.

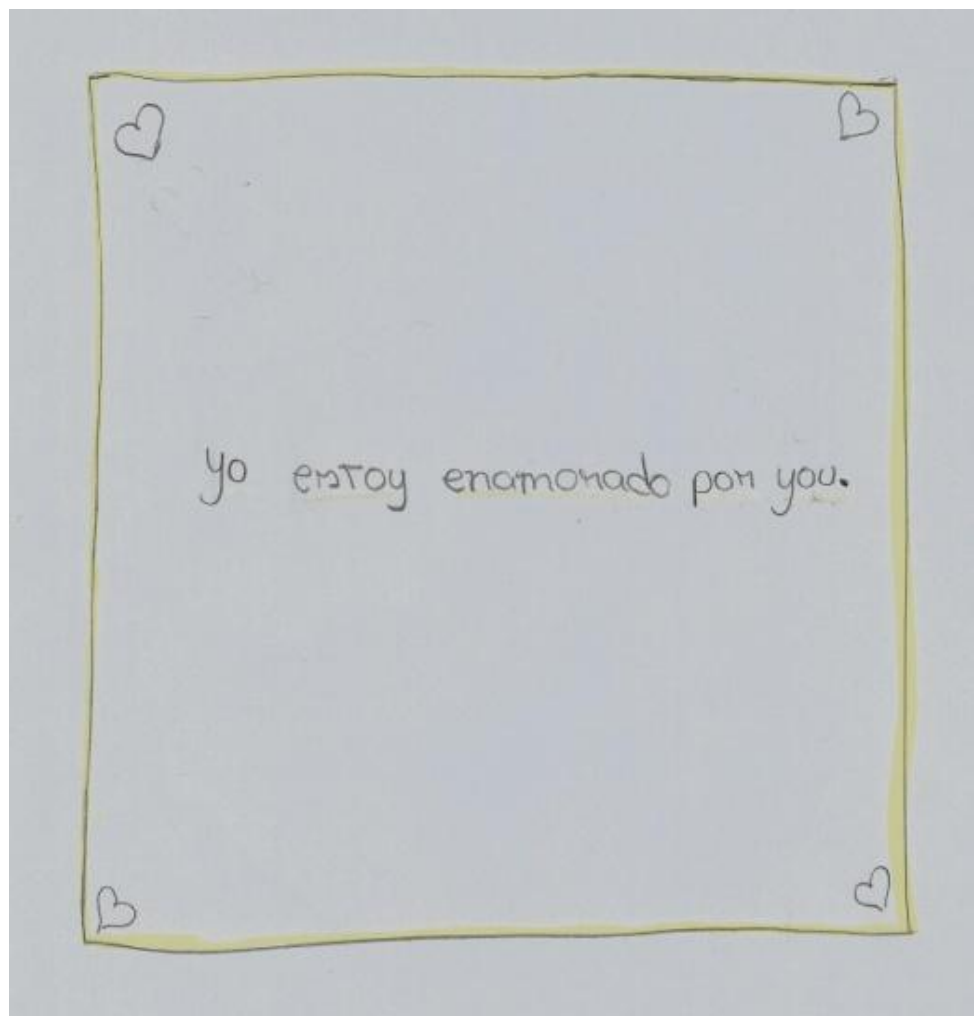

O texto da dupla M.F. e L.M. (figura 14) emprega o transidioma "esportinglês" por meio da frase "E ai brother já vou indo nessa, ¡Hasta la vista!”. Na construção multimodal dos alunos, frisamos o uso do termo brother do inglês para mostrar a proximidade do produtor do texto com o leitor, o que evidencia ser uma palavra muito usada nas práticas sociais rotineiras dos alunos, ao passo que a expressão de saudação “ ¡Hasta la vista!” faz referência a famosa frase do ator Arnold Schwarzenegger, proferida em 1991 no filme " $O$ Exterminador do Futuro 2: o julgamento final”. Ressaltamos que quase sempre, nas aulas de espanhol desta escola pública, os alunos 
brincam verbalizando essa frase, o que mostra o uso concreto do transidioma no dia-a-dia deles, pelo menos no âmbito escolar. A dupla M.F. e L.M. usou recursos verbais escritos na cor verde para construir significados no texto. O texto de M.K.M. (figura 15) usa o "portinglês" dentro de um balão de fala com a palavra stop, que se mostra como elemento imagético para representar a voz de uma pessoa verídica ou imaginária.

Figura 14 - Texto multimodal produzido pela dupla M.F. e L.M.

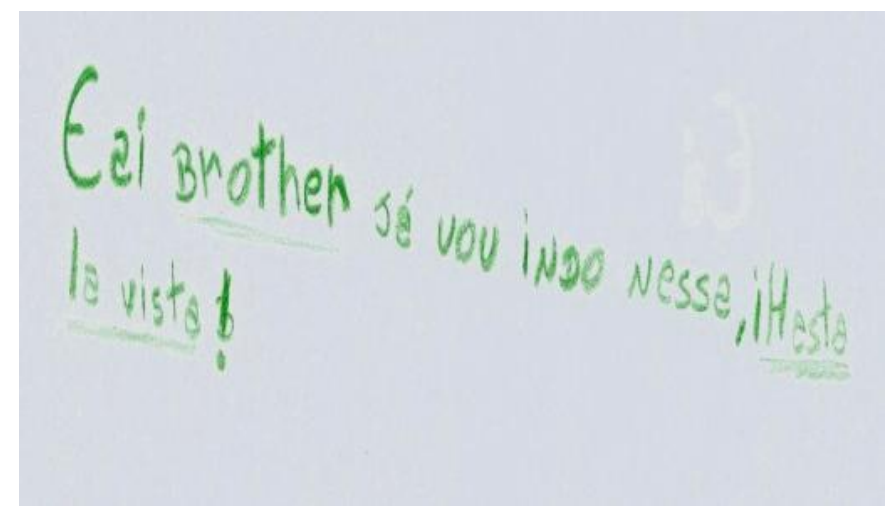

Figura 15 - Texto multimodal produzido por M.K.M.

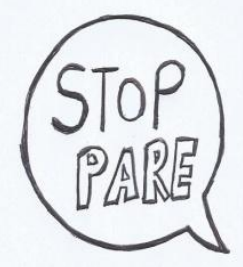

A dupla J.B.S e R.P. nos chamou bastante a atenção, pois o texto multimodal criado nos parece um desabafo, visto que o aluno J.B.S. se mostra introspectivo e triste em sala de aula e, nas reuniões de 
pais da escola, pudemos perceber que ele tem vínculos familiares fragilizados. Identificamos, no texto em questão, palavras de cunho pejorativo como: "xingar", "vai pra baixa da égua", "escarrar pra vea" (significando "falar mal para a velha"), "seu desmiolado", "seu muleque", "vai pra tu ver se te quebro seu merda", "pivete", "seu bostinha forever", "zé ninguém". Do inglês, os alunos utilizaram uma única palavra que enfatizou o teor negativo do xingamento, ao passo que, do espanhol, eles utilizaram a famosa frase de despedida "hasta la vista", por duas vezes. São notórias também as marcas de oralidade como "mam nam" (significando "macho, não"), reducionismos de palavras como "vó", além de representações típicas das conversas pela internet ou de mídias digitais como "kkkk". Há também palavras oriundas das variações linguísticas do Ceará como os termos "cumade" e "oxe". Dessa forma, identificamos nítidas nuances do discurso da periferia nas vozes silenciadas de adolescentes pobres e vítimas de violência doméstica e/ou negligência familiar, o que nos faz ver que a dupla representa a juventude que clama por visibilidade social. Paralelamente a isso, percebemos que a multimodalidade foi usada na diferenciação das cores azul e vermelho, com o intuito de enfatizar e destacar algumas falas.

Figura 16-Texto multimodal produzido pela dupla J.B.S. e R.P.

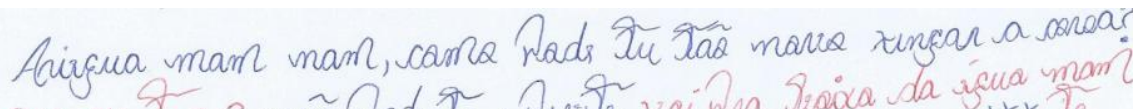

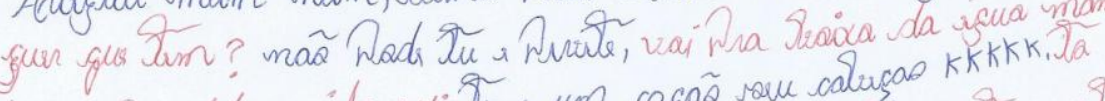
da minha vida acido sui tu is un cafäs sau catucas

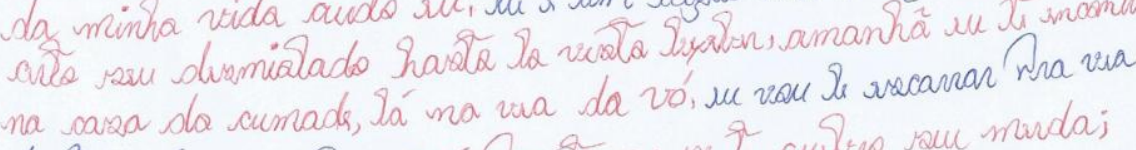

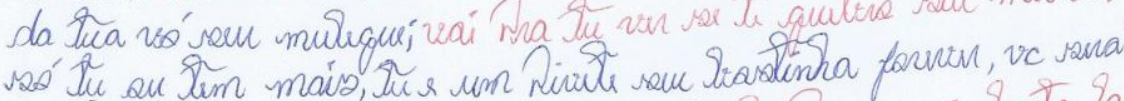

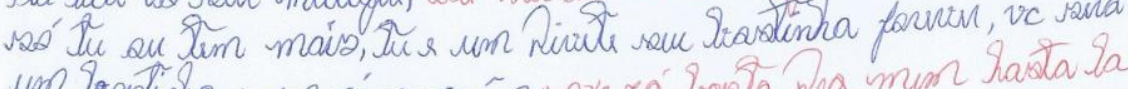

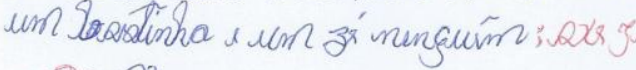
vialà. Than. 
Diante do exposto, enfatizamos que cada modo semiótico utilizado pelos alunos, dentro dos textos multimodais elaborados, foi criado para desempenhar um papel comunicativo, que deu suporte e contextualizou os usos transidiomáticos. Salientamos que o transidioma, atrelado aos modos semióticos empregados pelos alunos, carregou usos culturais, históricos e sociais, além de propósitos discursivos.

\section{Considerações finais}

Em linhas gerais, quantitativamente, constatamos que, dos quinze textos multimodais, em nove havia elementos imagéticos e escritos, na construção de sentidos. Em seis, foram usados exclusivamente caracteres escritos, porém, nestes, os alunos lançaram mão de aspectos modalizadores da escrita, tais como o tamanho, a tipografia e as cores das letras para realçar significados semióticos a fim de passar mensagens aos leitores. Salientamos que três textos multimodais representaram as mídias digitais, ou por elementos imagéticos ou por caracteres escritos.

Nesse sentido, defendemos que o uso do transidioma e da multimodalidade em sala de aula serviu, nesse caso específico, também para promover a socialização dos alunos, já que eles, ao construírem os textos multimodais, trocavam informações sobre o que e como elaborar os textos uns com os outros, compartilhando os recursos didáticos e os lápis de cores, dentre outros. Acreditamos que eles realmente se empolgaram e se esforçaram para realizar a atividade, pois alguns nos indagaram se poderiam utilizar determinada palavra ou recurso semiótico. Por isso, para tranquilizá-los, procuramos deixá-los "livres" e abertos ao processo criativo de construção dos textos multimodais, dizendo que tudo que eles quisessem produzir seria permitido se houvesse uma intencionalidade específica por parte do produtor do texto.

Dessa forma, percebemos que os usos transidiomáticos dos alunos foram permeados não apenas pelos idiomas inglês, espanhol e português, conforme Moita Lopes (2013) elenca, mas, no caso dos alunos adolescentes de uma escola pública e pertencentes a uma classe 
social menos favorecida socioeconomicamente, houve uso do "cearensês" e do "internetês". Isso fez com que tanto nós como os alunos refletíssemos sobre uma sociolinguística muito mais embebida no aparato social, vislumbrando os multiletramentos e valorizando a cultura local.

Os estudantes comentaram, depois da atividade, que eles perceberam o quanto a "favela" (sic) tem uma riqueza cultural linguística, pois, nos textos multimodais das entradas dos estabelecimentos comerciais, dos outdoors, dos grafites (também chamado por eles como "pichações"), das conversas virtuais rotineiras, é possível identificar aspectos como mobilidade, complexidade e imprevisibilidade na comunicação. Assim, os recursos semióticos são utilizados ou, às vezes, manipulados pelos falantes para realizar determinadas funções na realidade social em que estes jovens estudantes vivem.

Finalmente, com essa análise das práticas discursivas em sala de aula, almejamos mostrar que a reflexividade linguística no ensino de língua estrangeira é possível e necessária na rede pública de ensino, principalmente se as associarmos às teorias dos multiletramentos e da multimodalidade. A reflexividade serve como alicerce do processo de empoderamento social dos aprendizes, de modo a instigá-los a construir uma visão mais crítica e ativa na sociedade.

\section{Referências}

ARAÚJO, Antonia Dilamar. Gêneros multimodais: mapeando pesquisas no Brasil. Linguagem em Foco. Fortaleza: EDUECE, v. 1, n.1, p.13-23, 2011.

BEZEMER, Jeff; KRESS, Gunther. Changing text: a social semiotic analysis of textbooks. In: Designs for Learning. v. 3, n. 1/2, p.10-29, 2010 .

BLOMMAERT, Jan. Chronicles of complexity: ethnography, superdiversity, and linguistic landscapes. In: Tilburg Papers Culture Studies. Paper 29, Tilburg University: Netherlands. 2012. Disponível 
em: <https://www.tilburguniversity.edu/upload/19fb666f-300e-499bbadf-90204b0e89b1_tpcs\%20paper29.pdf>. Acesso em: 15 out. 2015.

BLOMMAERT, Jan. The sociolinguistics of globalization. Cambridge: Cambridge University Press, 2010.

BLOMMAERT, Jan; RAMPTON, Bem. Language and Superdiversity. Diversities. v. 13, n. 2, p. 01-21, 2011.

BULL, Geoff; ANSTEY, Michèle. The characteristics of multimodal texts: implications for the teaching of reading and writing. In: Evolving pedagogies: reading and writing in a multimodal world. Carlton South, Australia: Curriculum Press, 2010. p. 21-46.

CASTELLS, Manuel. A sociedade em rede. São Paulo: Paz e Terra, 1999.

JEWITT, Carey. An introduction to multimodality. In: JEWITT, Carey. (Ed.). The Routledge Handbook of Multimodal Analysis. London/New York: Routledge, 2010. p. 15-30..

KLEIMAN, Ângela. Modelos de letramento e as práticas de alfabetização na escola. In: KLEIMAN, Ângela. (Org.). Os significados do letramento: uma nova perspectiva social da escrita. 2. ed. Campinas, SP: Mercado das Letras, 2008. p. 15-61.

LABOV, William. Sociolinguistic patterns. Philadelphia: University of Pennsylvania Press, 1972.

LOURO, Guacira L. Gênero, sexualidade e educação: uma perspectiva pós-estruturalista. 16. ed. Petrópolis: RJ: Vozes, 2014.

MARTIN, Ivan. Síntesis: curso de lengua española (Ensino Médio). São Paulo: Ática, 2010.

MOITA LOPES, Luiz Paulo. Como e por que teorizar o português: recurso comunicativo em sociedades porosas e em tempos híbridos de 
globalização cultural. In: MOITA LOPES, Luiz Paulo. (Org.). Português no século XXI: cenário geopolítico e sociolinguístico. São Paulo: Parábola, 2013.p. 101119.

NEW LONDON GROUP. A Pedagogy of multiliteracies: designing social futures. In: COPE, Bill; KALANTZIS, Mary. (Orgs.). Multiliteracies: literacy learning and the design of social futures. New York: Routledge, 2006 [1996]. p. 9-37.

ROJO, Roxane Helena R. Pedagogia dos multiletramentos. In: ROJO, Roxane Helena R; MOURA, Eduardo (Orgs.). Multiletramentos na escola. São Paulo: Parábola Editorial, 2012. p. 11-31.

ROYCE, Terry D. Multimodal communicative competence in second language context. In: ROYCE, Terry D.; BOWCHER, Wendy L. (Eds.). New directions in the analysis of multimodal discourse. London: Routledge, 2006. p. 63-109.

SANTOS, Boaventura S.; MENESES, Maria Paula. Epistemologias do sul. São Paulo: Cortez, 2010.

SILVA, Daniel N. Diálogos intermídias, ou políticas de identidades em sala de aula. Trabalhos em Linguística Aplicada, v. 52, n.1, p. 147163, 2013.

SILVERSTEIN, Michael. Indexical order and the dialectics of sociolinguistic life. Language \& Communication, v. 23, p.193-229, 2003.

SOARES, Magda. Novas práticas de leitura e escrita: letramento na cibercultura. Educação \& Sociedade, v. 23, n. 81, p. 143-160, 2002.

Recebido em: 05/07/2016 Aceito em: 02/10/2016

Title: Transidiomatic practices in Spanish as a Second Language: multimodality in the public school 